\title{
Sweet electronics: honey-gated complementary organic transistors and circuits operating in air
}

\section{Alina S. Sharova, Mario Caironi*}

\author{
A. S. Sharova, Dr. M. Caironi
}

Center for Nano Science and Technology @PoliMi, Istituto Italiano di Tecnologia, Via G. Pascoli, 70/3, 20133 Milano, Italy.

E-mail: mario.caironi@iit.it

\author{
A. S. Sharova \\ Department of Physics, Politecnico di Milano, Piazza Leonardo da Vinci, 32, 20133 Milano, \\ Italy.
}

Keywords: edible electronics, organic electronics, electrolyte gated transistors, printedelectronics, honey

\section{Abstract text:}

Sustainable harnessing of natural resources is key moving towards a new-generation electronics, which features a unique combination of electronic functionality, low cost, and absence of environmental and health hazards. Within this framework, edible electronics, of which transistors and circuits are a fundamental component, is an emerging field, exploiting edible materials that can be safely ingested, and subsequently digested after performing their function. Dielectrics are a critical functional element of transistors, often constituting their major volume. Yet, to date, there are only scarce examples of electrolytic food-based materials able to provide low-voltage operation of transistors at ambient conditions. In this context, we propose a costeffective and edible substance, honey, to be used as electrolytic gate viscous dielectric in organic electrolyte gated field-effect transistors (HGOFETs). Both n- and p-type HGOFETs are demonstrated, with distinctive features such as low voltage $(<1 \mathrm{~V})$ operation, long-term shelf life and operation stability in air, and compatibility with large-area fabrication processes, such as inkjet printing, on edible tattoo-paper. Such complementary devices enable robust honeybased integrated logic circuits, here exemplified by inverting logic gates and ring oscillators. A marked device responsivity to humidity provides promising opportunities for sensing applications, specifically, for moisture control of dried or dehydrated food. 


\section{Introduction}

Steering the technological development in a sustainable direction has become mandatory. The acknowledgment of the global problem of electronic and plastic waste and its consequences, posing severe risks to the environment and human health, asks for drastic countermeasures. For this reason, the demand for readily available natural resources for the design and fabrication of "benign” electronic solutions is growing. As a result, recently, an increased emphasis has been placed on the investigation of alternative organic, green, and biodegradable electronics. ${ }^{[1-3]}$ When the electronic technology faces the healthcare and food sector, safety of the devices becomes mandatory. The latter is particularly critical when the electronic systems are intended to explicitly interact with the inside of the human body, be ingested either along with the consumed food or pharmaceutical products. In this framework, ingestible electronics has so far achieved remarkable advances paving the way for a new era diagnostics and therapy. ${ }^{[4-8]}$ However, ingestible systems available to date, ${ }^{[9]}$ apart from their bulk design and need of postperformance recollection, have critical drawbacks manifesting primarily in the use of toxic and not disposable materials, posing hazards not only to the consumer health, but also to the environment.

To this end, the recently conceptualized “edible electronics” ${ }^{[10-12]}$ envisions electronic systems fulfilling key electronic functionalities, being sustainable, nontoxic, safe for ingestion, and costeffective at the same time. The unique feature of this emerging field lies in exploiting edible materials of different nature (e.g. food, drugs, edible metals, edible pigments, dyes and polymers) as electronics constituents, according to their electronic properties, to provide all the necessary building blocks: conductors, insulators, semiconductors. Due to the absolute safe composition, edible devices are intended to undergo degradation within the body after accomplishing their task, what implies elimination of any potential adverse effects.

Being at an emerging stage, the field is scarce in examples. Yet the feasibility of this new paradigm relies on several inspiring and rather exotic prototypes of edible, and in particular 
food-based electronic components, such as cheese supercapacitors ${ }^{[13]}$, broccoli microphones ${ }^{[14]}$, charcoal-based biofuel cells ${ }^{[15]}$, silk sensors ${ }^{[16]}$, transistors based on edible pigments ${ }^{[12,17]}$, among others.

In order to fulfill the fundamental electronic duties of tracking, monitoring, sensing and data transmission, edible electronics system will require active circuits. In this context, transistors represent the backbone components of future edible systems, for which low-voltage/low-power operation is mandatory.

Edible transistors are exemplified so far by only few demonstrations realized primarily through vacuum-based thermal evaporation ${ }^{[12]}$ or printing techniques. ${ }^{[18]}$ By employing edible dielectrics (e.g., guanine, adenine, albumin, ethilcellulose, among others ${ }^{[12,18-20]}$ ), field-effect transistors (FETs), either entirely or partially edible, were demonstrated, with operational voltages in the range from 5 to $60 \mathrm{~V}$.

To lower the operation voltage and meet requirements of edible electronics, electrolyte-gated organic FETs (EGOFETs) appear a as a powerful option. In fact, because of very large typical areal capacitance $\left(\mu \mathrm{F} / \mathrm{cm}^{2}\right),{ }^{[21]}$ operational voltages $<1 \mathrm{~V}$ can be adopted. Moreover, EGOFETs provide coupling of both ionic and electronic domains in a single device, what opens various opportunities for sensing applications. ${ }^{[22-25]}$ Among widely investigated electrolytic compounds (e.g. ionic liquids, ion-gels, aqueous and solid-state electrolytes), ${ }^{[26-29]}$ pure/distilled water is a common gating media. ${ }^{[30-33]}$ While acqueous gating is being exploited for biosensing assays, ${ }^{[34-}$ ${ }^{36]}$ a liquid gating phase clearly poses issues in circuits integration.

A strategy to overcome this limitation is represented by the exploitation of electrolytic properties of food stuff to implement edible gating media in EGOFETs. Herein, we investigate electrical performance of a low cost, widely accessible and edible by definition substance, honey, as an electrolytic gate dielectric within the EGOFET architecture. Honey is recognized as a supersaturated viscous electrolytic solution that contains mainly sugars ( $>80 \mathrm{wt} \%$; fructose, glucose, sucrose), water (<17\%) and minor components (enzymes, amino and other acids, lipids, 
proteins, vitamins, minerals, and others) in varying quantities depending on the honey origin and environmental conditions. ${ }^{[37]}$ Besides showing ionic conductivity related to its hydration state, ${ }^{[38]}$ honey is characterized by intrinsic properties of long shelf life, high viscosity, hygroscopicity, antioxidant capacity and antibacterial activity, ${ }^{[39,40]}$ what makes this nutritive sweet compound an appealing candidate for applications in convergence of healthcare, biology and electronics.

The approach of using honey as electrolyte gate dielectric has been so far proposed only to gate graphene for a rapid determination of its quality. ${ }^{[41]}$ No honey-gated devices or integrated circuits based on organic and edible materials, have been, however, reported until now.

In this work we demonstrate air-stable, low-voltage, p-type and n-type honey-gated OFETs (HGOFETs), and their combination in complementary inverting logic gates and ring oscillators. We also show the compatibility of our HGOFETs with fabrication on an edible flexible tattoopaper substrate, which could be conformally adhered to different surfaces, in particular, food items. The introduction of honey as a non-toxic, commercially available, cost effective, and easily processable electrolyte gate dielectric is potentially advantageous for various edible electronics applications ranging from biomedicine to food industry.

\section{Results}

In order to verify the intrinsic electronic performance of honey as a gating media for polymer semiconductors, a first set of HGOFETs was realized on rigid glass substrates, serving as a reference. A schematic cross-section of top-gate bottom-contact HGOFETs configuration is shown in Figure 1a. Gold source and drain electrodes were patterned by photolithography, with the channel length $L$ and the channel width $W$ of $10 \mu \mathrm{m}$ and 20,000 $\mu \mathrm{m}$, respectively.

Given the substantial lack of proved edible, high-performance solution processible organic semiconductors, two well-known model polymers were used in our tests to demonstrate the compatibility of HGOFETs with both hole and electron transporting materials. One of the most 
extensively studied good hole transporting polymer semiconductors, poly(3-hexylthiophene) (P3HT), the biocompatibility of which has been widely recognized, ${ }^{[42-44]}$ was employed for ptype HGOFETs. Poly\{[N,N’ -bis(2-octyldodecyl)-naphthalene-1,4,5,8-bis(dicarboximide)2,6-diyl]-alt-5,5' -(2,2' -bisthiophene) $\}$ (P(NDI2OD-T2)), an intensively investigated electron transporting copolymer, was, on the other hand, used in n-type devices. In terms of biocompatibility, the latter has been so far subjected to cytotoxicity tests only, with no adverse effects detected for proliferation of line cells such as HUTU-80 and CACO-2. ${ }^{[18]}$

The aforementioned P3HT and P(NDI2OD-T2) polymers were spin-coated onto the substrates provided with the interdigitated contacs, and a drop of commercially available honey (see the experimental section for details) was than cast on the semiconductor surface at ambient conditions (Figure 1a, b). A tungsten tip was subsequently dipped in honey to serve as a gate electrode.

When an external negative voltage is applied to the gate tip for p-type operation, cations accumulate at the gate/honey interface, while anions are repelled towards the honey/semiconductor interface, producing the accumulation of holes in the semicondutor. The reverse charge distribution occurs in n-type gating, when the positive potential is applied to the gate.

The current-voltage $(I-V)$ transfer and output characteristics of the p-type and n-type devices are given in Figure 1c and 1d, correspondingly. The curves presented demonstrate a typical FET operation in both linear (drain-source voltage $V_{\mathrm{ds}}$ of $\pm 10 \mathrm{mV}$ and $\pm 50 \mathrm{mV}$ ) and saturation regimes $\left(V_{\mathrm{ds}}= \pm 1 \mathrm{~V}\right)$ at absolute gate voltages $V_{\text {gate }}$ below $1 \mathrm{~V}$. The threshold voltage $V_{\text {th }}$ was found to be $\sim 0.25 \mathrm{~V}$ for P(NDI2OD-T2)-based HGOFETs and $\sim-0.35 \mathrm{~V}$ for P3HT-based HGOFETs at $V_{\mathrm{ds}}= \pm 1 \mathrm{~V}$. The transfer voltage sweeps exhibit a modest hysteresis and a more evident $V_{\mathrm{ds}}$ dependent threshold voltage shift, which might be related to field-dependent charge injection. ${ }^{[45,46]}$ A distinctive feature of the demonstrated HGOFETs is their reproducibility 
(Figure S1) and stable operation in air, at room temperature (relative humidity, RH, of about 50\%). Devices revealed a shelf-life stability up to one month control period, while being stored in air (Figure S2), with no evidence of electronic performances degradation (RH varied from 48.8 to 50.4\%). The shelf-life of HGOFETs was limited by the time of naturally occuring honey crystallization, that exceeded in our case the control period of one month. Operational stability of the devices has been as well preliminarly validated through a continuous cycling voltage test (30 min total duration) performed in air by switching the devices on and off (Figure S3).

Interestingly, the OFETs based on the chosen polymer semiconducotors typically show a poor air stability. In particular, P3HT is known to be subjected to photodoping upon exposure of the material to light in air, ${ }^{[35,47-50]}$ which can drastically limit charge modulation and the on/off current ratio of the device. P(NDI2OD-T2) charged with an excess electron undergoes on the other hand oxygen and water-induced irreversible degradation processes. ${ }^{[51-53]}$ The drastically improved ambient stability conferred by honey, cast onto the semiconductors surface, indicates that it additionally acts as an encapsulant forming a kinetic barrier against diffusion of water and oxygen into the active channel region. The origin of this effect requires more detailed investigation, but is likely related to the low water activity of honey, of about 0.6 , and its high osmotic pressure. ${ }^{[39,40]}$ Fresh fruits and vegetables, for example, have water activity of around 0.99, whereas the water activity of pure water is $1 .{ }^{[54]}$ We anticipate that the specific viscosity of the selected honey may modulate gating, as well as, barrier properties. ${ }^{[55]}$

As a characteristic figure of merit of electrolyte-gated transistors, the mobility-capacitance product $\mu_{\text {sat }} C$ has been extracted for HGOFETs from the transfer characteristic curves in the saturation regime according to:

$\mu_{\mathrm{sat}} \cdot C=\frac{2 L}{W}\left(\frac{\partial \sqrt{I \mathrm{ds}}}{\partial V \text { gate }}\right)^{2}$

where $\mu_{\mathrm{s}}$ is the mobility in the saturation regime, $C$ is the gate capacitance per unit area, $I_{\mathrm{ds}}$ is the drain current, $V_{\text {gate }}$ is the gate voltage. The determined $\mu_{\text {sat }} C$ values are $\approx 23 \mathrm{nF} \mathrm{V}^{-1} \mathrm{~s}^{-1}$ for p- 
type and $\approx 3.5 \mathrm{nF} \mathrm{V}^{-1} \mathrm{~s}^{-1}$ for n-type HGOFETs. Both values are one order of magnitude higher than those previously obtained in water-gated organic FETs (WGOFETs), with identical architecture, based on the same polymers and characterized within the same range of voltages (Table 1). In order to make a demonstrative comparison of the two configurations, the areal capacitance values $C$ of metal-insulator-semiconductor (MIS) structures, consisting of $\mathrm{Au} / \mathrm{honey} /$ semiconductor/Au, were evaluated at $0.1 \mathrm{~Hz}$ from electrical impedance spectroscopy (EIS) measurements (Figure S4, Average impedance with standard deviation among 3 samples). $C$ was found to be $2.3 \mu \mathrm{F} \mathrm{cm}^{-2}$ for the P3HT based MIS with the polymer thickness of $35 \mathrm{~nm}$, and $1 \mu \mathrm{F} \mathrm{cm}^{-2}$ for the P(NDI2OD-T2) one with the polymer thickness of $32 \mathrm{~nm}$. The capacitance values obtained are compatible with an interface field-effect, rather than a volumetric one, suggesting that ions from the honey do not penetrate into the bulk of the semiconductor. The formation of an electrical double layer is in agreement with previously reported studies on WGOFETs involving the same hole transporting material ${ }^{[56]}$ and additional experiments realized for honey-based devices with different semiconductor thicknesses (Figure S5-6). Additionally, we observed that the electrical properties of HGOFETs and HGOFETs based circuits were not affected by the quantity/thickness of the honey drop when hydrated. The depth of the gate electrode immersed in honey neither influenced the devices electrical performance. The average volume of the honey drop was $20 \mu \mathrm{L}$, however, significantly varied from device to device without affecting quantitatively or qualitatively their input or output electrical characteristics (Figure S1). This is consistent with the fact that EDL is an interface phenomenon, and its formation should not depend on the electrolyte thickness. We, therefore, expect no capacitance dependence on the quantity of the honey drop.

We attribute the electrolyte gating behavior of honey to its marked hygroscopic nature, i.e. its ability to absorb/reabsorb moisture from the surrounding environment due to the low water activity. In this scenario, at ambient conditions, the movement of ionic honey species within the honey matrix is enabled by presence of water. The diffusion of ions within honey under the 
influence of the applied electrical field is, hence, directly dependent on the honey moisture content. The likelihood of hydrolysis of water present in honey, which might drastically impact the devices performance, is eliminated since the applied voltage range does not exceed the minimum voltage stimulating water decomposition equal to $1.229 \mathrm{~V}$ at $25^{\circ} \mathrm{C} .{ }^{[57]}$

Given the above picture, hydration of honey is critical to its gating properties. As a further confirmation, we tested the effect of honey dehydration by transferring HGOFETs devices to an inert nitrogen environment, with $\mathrm{RH} \approx 0 \%$. As a consequence of storing the devices in inert atmosphere, a first significant threshold voltage $V_{\text {th }}$ increase for both the p and n-type HGOFETs was registered within hours (Figure 1e, f). Over a period of one month, $V_{\text {th }}$ reached equilibrium, with an overall increase of two orders of magnitude with respect to its value for hydrated honey, reaching $-28 \mathrm{~V}$ and $13 \mathrm{~V}$ in saturation for $\mathrm{p}$ and n-type HGOFETs, respectively. In the absence of absorbed water, ionic conductivity is compromised and the capacitance is drastically reduced $\left(C=0.05 \mathrm{nF} \mathrm{cm}^{-2}\right)$, to a level expected in non-electrolytic dielectrics, with a corresponding need of very high voltages to accumulate an electronic channel in the semiconductors (Figure S7). Once honey is rehydrated, by transferring the devices back to ambient atmosphere ( $\mathrm{RH} \approx 50 \%$ ), HGOFETs recover the original low voltage operation as an effect of electrolyte-gating within few minutes (Figure S8-9). 
$V_{\text {th }}$ for the p-type and (f) n-type HGOFET operating in both linear $\left(V_{\mathrm{ds}}= \pm 0.05 \mathrm{~V}\right)$ and saturation $\left(V_{\mathrm{ds}}= \pm 1 \mathrm{~V}\right)$ regimes. The rectangular regions correspond to the hydration of the dehydrated devices right after exposing them to air.

Table 2. The comparison of the electrical characteristics (areal capacitance $C$, mobilitycapacitance product $\mu_{s} * C$ ) between honey-gated and previously reported water-gated transistors. The capacitance values are extracted from EIS measurements at $0.1 \mathrm{~Hz}$.

\begin{tabular}{lll}
\hline & $\begin{array}{l}C \\
{\left[\mu \mathrm{Fcm}^{-2}\right]}\end{array}$ & $\begin{array}{l}\mu_{\mathrm{s}}{ }^{*} \mathrm{C} \\
{\left[\mathrm{nFV}^{-1} \mathrm{~s}^{-1}\right]}\end{array}$ \\
\hline P3HT WGOFET ${ }^{[59]}$ & 2 & 6 \\
P3HT HGOFET & 2.3 & 23 \\
\hline P(NDI2OD-T2) WGOFET ${ }^{[58]}$ & 0.08 & 0.3 \\
P(NDI2OD-T2) HGOFET & 1 & 3.5 \\
\hline
\end{tabular}

The demonstrated operability of HGOFETs and the possibility to realize both n-type and p-type devices allow the realization of complementay logic circuits, the most robust logic circuits topology, gated through honey. We first implemented a complementary logic inverter based on the aforementioned HGOFETs. Figure 2a reports a visual representation of a honey-based complementary inverter, the geometrical parameters of which were chosen to balance the currents of the n- and p-type devices (p-type: $L=20 \mu \mathrm{m}, W=20,000 \mu \mathrm{m}$; n-type: $L=10 \mu \mathrm{m}$, $W=20,000 \mu \mathrm{m})$. As a result, a balanced device operation with symmetrical voltage-transfer characteristics (VTC) and negligible hysteresis was obtained (Figure 2b). The inversion threshold ( $\left.V_{\text {inv }}\right)$ is correctly placed at half of the supply voltage $\left(V_{\mathrm{DD}} / 2\right)$, being $\sim 0.5 \mathrm{~V}$ at $V_{\mathrm{DD}}$ $=1 \mathrm{~V}$ and $\sim 0.4 \mathrm{~V}$ at $V_{\mathrm{DD}}=0.8 \mathrm{~V}$. The inverter shows a high gain of $\sim-19$ at the logic transition at $V_{\mathrm{DD}}=0.8 \mathrm{~V}$.

The correct operation of the honey-gated inverter allowed us to combine them in a ring oscillator (Figure 2c), to demonstrate the use of HGOFETs in complementary circuits. The output signal of the three-stage honey-based ring oscillator at various $V_{\mathrm{DD}}$ is reported in Figure 2d,e. The increase of the device oscillation frequency $\left(f_{\text {osc }}\right)$ from $0.32 \mathrm{~Hz}$ to $0.67 \mathrm{~Hz}$, along with 
the decrease of the stage delay from 0.53 to $0.25 \mathrm{sec}$, is observed with raising $V_{\mathrm{DD}}$ from 0.4 to 1.2 V. The ring oscillator itself is proved to be sensitive to the hydration of honey. In fact, its electrical parameters, such as the oscillation amplitude and $f_{\text {osc }}$ drastically change from ambient $(\mathrm{RH} \approx 50 \%)$ to inert atmosphere $(\mathrm{RH} \approx 0 \%$, Figure $2 \mathrm{f})$. In particular, $f_{\text {osc }}$ measured at a fixed $V_{\mathrm{DD}}=1 \mathrm{~V}$ decreases from $0.6 \mathrm{~Hz}$ in ambient atmoshere to $0.02 \mathrm{~Hz}$ after 4 days of storage in inert atmosphere (Figure S10). The reverse process, with $f_{\text {osc }}$ raising again to $0.62 \mathrm{~Hz}$, occurs within minutes after re-exposing the circuit to air.

The control of relative humidity can be critical for many applications, in particular, for food and beverages or healthcare industries, where the quality of the products can strongly depend on the moisture content of the atmosphere they are exposed to. Therefore, targeting the concept of safe and edible electronic systems, HGOFETs and HGOFETs-based circuits could potentially be integrated as reversible humidity indicators of humidity/dry conditions, more specifically, for moisture monitoring of dried or dehydrated food (e.g., food packaging).

On the other hand, the humidity-dependent behavior of honey may pose a stability issues for circuits. Monitoring the devices in ambient conditions at varied humidity over a month period (Figure S2), we observed that within a $\mathrm{RH}$ range of $45-60 \%$ no major variations in electrical properties of the devices occur, thus indicating that the gating properties of honey are preserved. This is in agreement with previous studies reporting no drastic variation of moisture content in honey in the same $\mathrm{RH}$ range. ${ }^{[60]}$ When such $\mathrm{RH}$ conditions cannot be ensured, to achieve stability on a broader range of humidity values, the moisture content of honey could be potentially preserved by, for example, encapsulating it with beeswax, an authorized food additive (E901). Such encapsulation would replicate the honeycomb, which is naturally intended for honey moisture content preservation. 

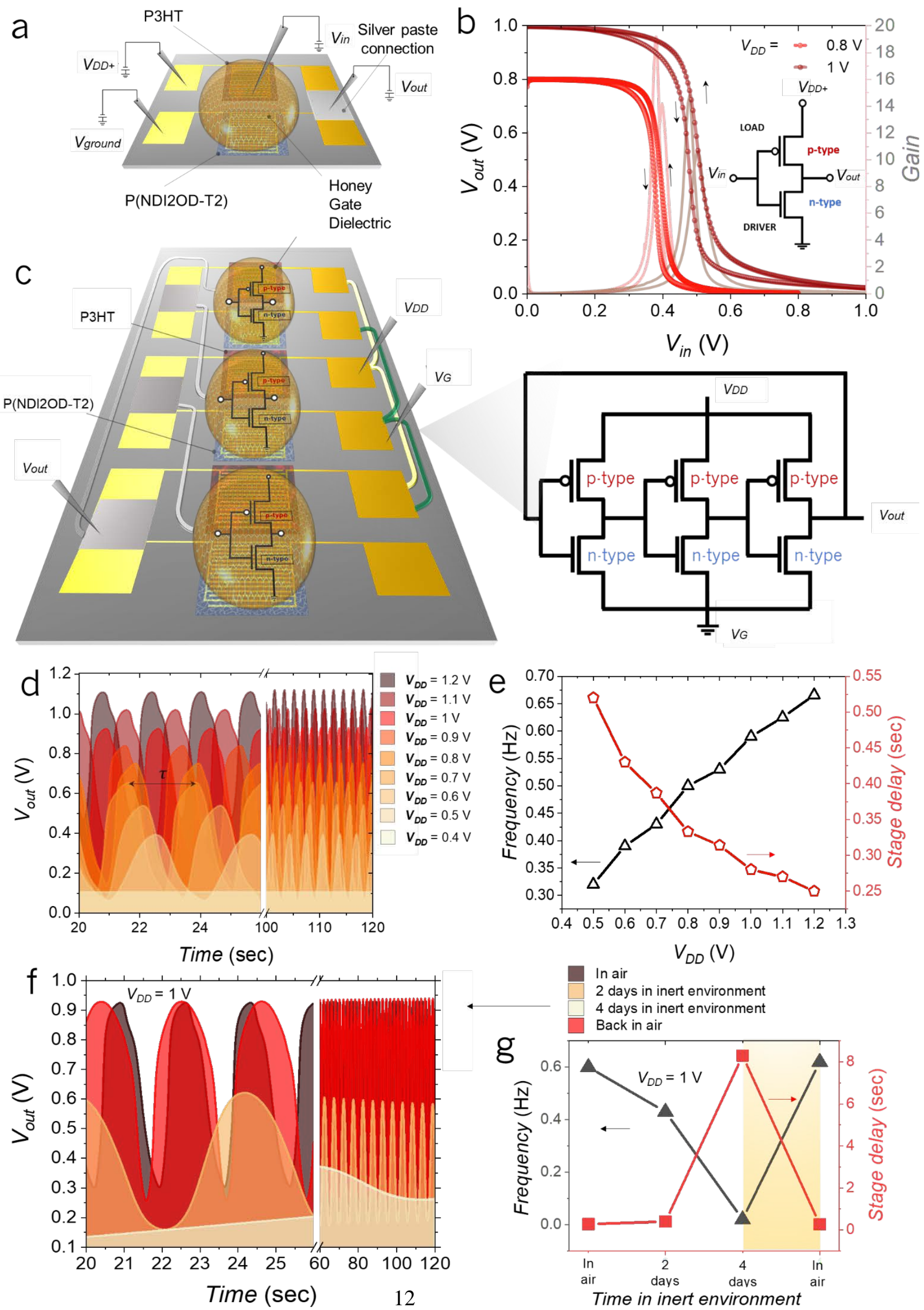
Figure 2. HGOFETs-based logic circuits and their electrical characterization (a) Schematic representation of the inverting logic gate device realized with P3HT and P(NDI2ODT2). (b) VTCs, and corresponding derivative curves to extract gain, of a complementary HGOFETs-based inverter as a function of input voltages; the arrows indicate the sweep (rate of $25 \mathrm{mV} \mathrm{s}^{-1}$ ) direction; the inverter configuration is reported as an inset. (c) Schematic representation (left) and the circuit configuration (right) of the three-stage HGOFETs-based ring oscillator. (d) Output waveforms of the HGOFETs-based oscillator operating in air at different supply voltages $V_{\mathrm{DD}}$. (e) Output oscillation frequency (black line) and propagation signal delay per stage (red line) of the HGOFETs-based oscillator operating in air as a function of $V_{\mathrm{DD}}$. (f) Output waveforms of the HGOFETs-based oscillator at different humidity conditions (in air; in inert environment) at $V_{\mathrm{DD}}=1 \mathrm{~V}$. (g) Output oscillation frequency (black line) and stage delay (red line) of the HGOFETs-based oscillator as a function of the humidity condition. The rectangular region schematically corresponds to the hydration of the dehydrated device right after exposing it to air.

Finally, as a proof of concept, we aimed at demonstrating the possibility to transfer the airstable low-voltage HGOFETs on edible items, in particularly food, by exploiting temporary tattoo-paper substrate. ${ }^{[18]}$

To this end, the interdigitated source and drain electrodes of the HGOFETs $(L=100 \mu \mathrm{m}, W=$ 20,000 $\mu \mathrm{m}$ ) were patterned through thermal shadow-mask evaporation of gold onto the ethylcellulose (EC) surface of the tattoo paper. The biocompatible P3HT active layer was inkjet-printed, and the honey was then drop-cast to cover the HGOFETs channel area.

The transfer of the devices was achieved by aqueous dissolution of the sacrificial starch/dextrin layer, and release of the sub-micrometric film of EC onto the target item by sliding it off the paper backing. The electrical characterization in saturation regime $\left(V_{\mathrm{ds}}=-0.7 \mathrm{~V}\right)$ shows that the tattoo-paper approach allows the correct low voltage $\left(V_{\text {gate }}<1 \mathrm{~V}\right)$ operation of the p-type HGOFETs before (Figure S11) and after (Figure 3a,b) the demonstrative device transfer onto the apple skin. The threshold voltage of the transferred device was found to be $\sim 0.75 \mathrm{~V}$ at $V_{\mathrm{ds}}$ $=-0.7 \mathrm{~V}$. Our experiments overall demonstrate that by means of untreated commercial tattoopaper, HGOFETs can be easily deployed onto various surfaces, in particular, food items (Figure 3c). 

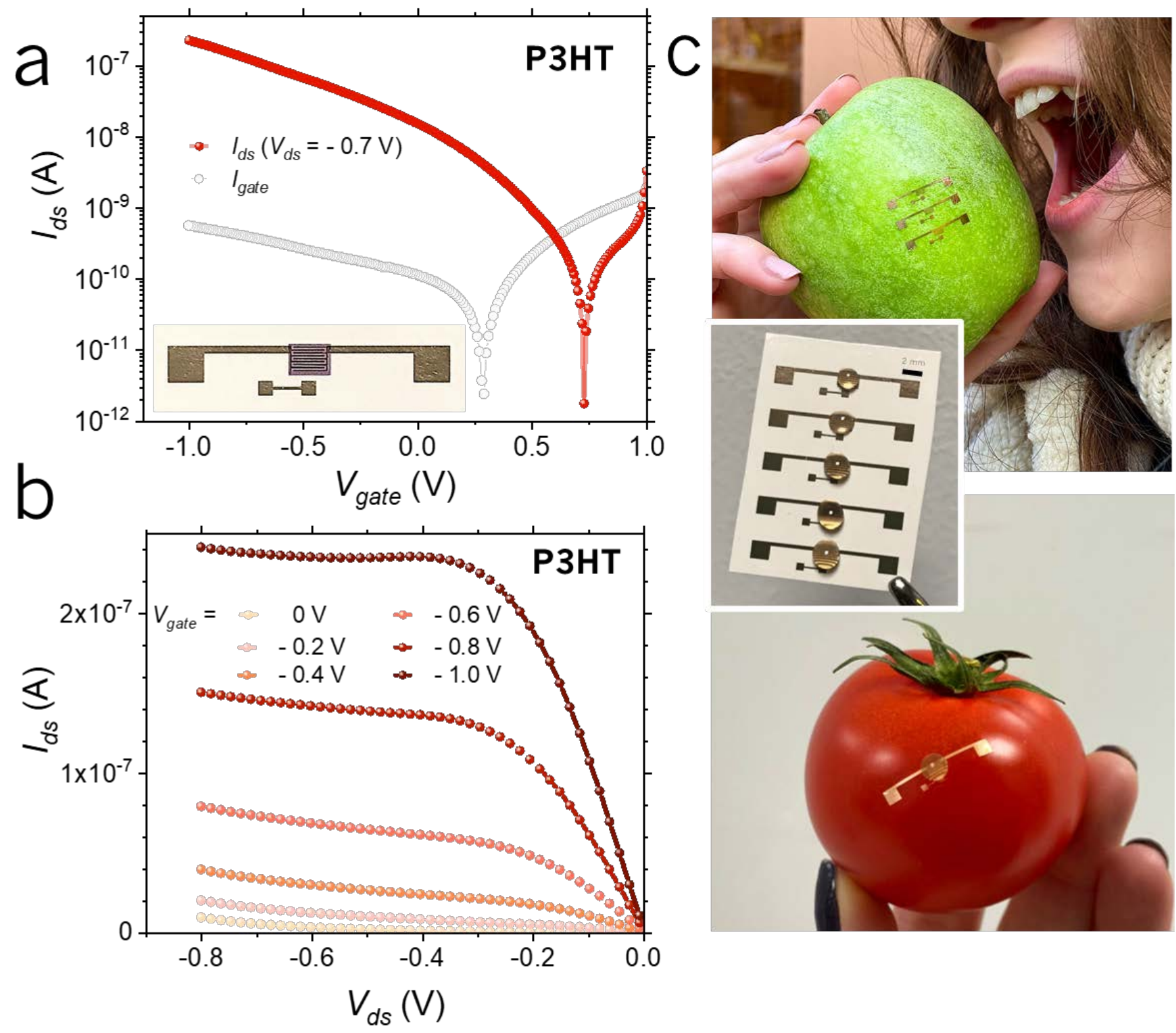

Figure 3. HGOFETs on flexible edible tattoo-paper substrate: electrical characterization and devices conformability. (a) Transfer in saturation $\left(V_{\mathrm{ds}}=-0.7 \mathrm{~V}\right)$ regime and (b) output characteristic curves for p-type HGOFET after the transfer onto the apple surface. (c) Digital photograph of HGOFETs (in the middle), HGOFETs transferred onto different food items: an apple (top) and tomato (bottom).

The final configuration of the HGOFET employs to a greater extent edible nature - derived and commodity materials in the design. The device was assembled on the substrate of a cellulose derivative, EC, a food additive (E462) approved by Food and Drug Administration (FDA) and widely used as a coating agent, emulsifier, binder or filler in the pharmaceutical, cosmetics and food technologies. The electrically conductive components of the device were realized in gold, 
a biologically inert stable substance. With a purity higher than 23 karat, gold is accepted in food industry as garnish to various food items (E175). Honey dielectric is an inherently nutritious edible compound that, owing to its complex chemical composition and physical properties, finds wide range applications not just in the food sector, but also in medicine. The compatibility of the adopted semiconducting polymers with ingestion, on the other hand, is the most critical requirment for the overall edibility of the final device, in spite of the extremely low quantity of active material exploited for the fabrication of a single HGOFET, in the range of picograms. ${ }^{[18]}$ Although P3HT has been recognized as a biocompatible material, and P(NDI2OD-2T) has been previously subject to cytotoxicity studies on cell lines derived from human GI tissue, the more profound complex analysis of polymers edibility is still needed, which will eventually require clinical tests. To prepare the ground for future edibility studies, we are currently applying in vitro digestion protocols to simulate the physiological conditions of devices during in vivo digestion and first assess safety, with special emphasis on the semiconducting materials.

\section{Conclusion}

In conclusion, we presented the use of honey, a naturally occurring and inexpensive food, as an electrolytic gate dielectric for organic transistors. Honey-gated complementary polymer transistors and logic circuits, namely, inverting logic gates and ring oscillators, operating in ambient air at low voltages, $<1 \mathrm{~V}$, were demonstrated.

Devices exhibit promising electronic performances in terms of mobility-capacitance product, negligible hysteresis, competing with or outperforming previously reported water-gated systems, based on the same polymers. We related the excellent gating features to the hydration of honey, which thanks to a rather low water activity absorbs water from the environment. Such characteristic donates to HGOFETs a strong sensitivity to relative humidity levels, suggesting a possible use as humidity indicators.Very interestingly, ambient operation and shelf-life stability are observed for devices based on non-environmentally stable semiconducting 
polymers, denoting an effective encapsulation capability of honey. Such effect would favor the development and application of future edible electronic circuits and systems. To this end, we also showed the compatibility of HGOFETs with release on food stuff from temporary papertatoo susbtrates. While the edibility of the adopted semiconducting polymers has not been assessed yet, with only biocompability and/or cytotoxicity data available, the latter demonstration offers a proof-of-concept platform for future low-power edible circuits.

Ongoing studies are focused on the first assessment of edibility of the employed active materials through in vitro digestion tests, and on the investigation of alternative semiconductors, such as natural dyes, for which edibility is already demonstrated.

We believe that such „sweet“ and functional honey-based devices hold a considerable promise for future development of edible electronics, and its integration to the healthcare sector.

\section{Experimental Section}

Materials: Semiconducting polymers regioregular P3HT (regioregularity $>99 \% ; \mathrm{M}_{\mathrm{W}}=17.5$ $\mathrm{kDa}$ ) and P(NDI2OD-2T) (Activink N2200, $\mathrm{M}_{\mathrm{n}}=26.6 \mathrm{kDa}$ and polydispersity (PDI) of 3.2) were purchased from Sigma-Aldrich and Flexterra Inc., respectively, and used as received without any further purification. Honey (Millefiori della Patagonia, LOT 19248-2, Eridania) was purchased from the supermarket, and used as it is, being stored in ambient environment. Commercial tattoo-paper (Tattoo 2.1) was acquired from The Magic Touch Ltd. and used without any cleaning or surface treatment, apart from dust removal by nitrogen flushing. Samples Preparation: P3HT was dissolved in chlorobenzene $\left(2.6 \mathrm{mg} \mathrm{mL}^{-1}\right)$ and P(NDI2OD2T) was dissolved in toluene $\left(5 \mathrm{mg} \mathrm{mL}^{-1}\right)$ by stirring the solutions at $\approx 80{ }^{\circ} \mathrm{C}$ and room temperature, respectively. The inks were regularly stirred at the corresponding temperatures for 20 min.

For HGOFETs we adopted a bottom-contact architecture. Thoroughly cleaned corning 1737F glass (sonication in acetone and isopropanol, followed by 10 min of oxygen plasma) was used 
as the substrate for the first set of experiments. Interdigitated Au source and drain contacts of $L$ $=10 \mu \mathrm{m}$ and $W=20,000 \mu \mathrm{m}$ were defined by a lift-off photolithographic process. A Cr adhesion layer (thickness: $\sim 1 \mathrm{~nm}$ ) and a Au layer (32 nm) were thermally evaporated. The substrates were rinsed with isopropanol before deposition of the semiconductor. The formulations of P3HT and P(NDI2OD-2T) were deposited by spin-coating at $1000 \mathrm{rpm}$ for $30 \mathrm{~s}$ in air, and finally annealed at $90{ }^{\circ} \mathrm{C}$ and $120^{\circ} \mathrm{C}$, correspondingly, for $20 \mathrm{~min}$ in an inert environment to remove residual solvents. The honey was then drop-cast onto the channel area, and a tungsten probe was immersed in honey to serve as a gate electrode. The HGOFETs-based inverting logic gate and ring oscillator were fabricated with connections realized with silver paste or wires. Another set of HGOFETs has been assembled directly onto commercial tattoo-paper substrate. $\mathrm{Au}$ source and drain contacts were deposited through a shadow mask by vacuum thermal evaporation to achieve $L=100 \mu \mathrm{m}$ and $W=20,000 \mu \mathrm{m}$. The P3HT formulation was inkjetprinted directly onto the contact and channel area with the Fujifilm Dimatix, DMP2831, and annealed at $\approx 120^{\circ} \mathrm{C}$ for 20 min in inert environment. A honey drop was than cast, with tungsten probe served as a gate electrode. Transfer of the devices on food surfaces was performed by soaking the tattoo-paper substrate in MilliQ water to achieve the dissolution of the sacrificial starch/dextrin layer, and subsequent release of EC onto the target item by sliding it off the paper carrier. A honey drop was than cast onto the transferred device.

Devices Characterization: Measurements of the HGOFETs and HGOFETs-based circuits characteristic curves were performed both in air and in inert atmosphere (nitrogen filled glovebox, $\mathrm{O}_{2}$, and $\mathrm{H}_{2} \mathrm{O}$ levels below 1 ppm) by means of an Agilent B1500A Semiconductor Parameter Analyzer. All the devices have been measured in "yellow" room under the light filtered below $500 \mathrm{~nm}$. The devices were periodically exposed to the microscope white light in order to probe the sample. Mobility-capacitance product values and threshold voltages were obtained by a linear fitting of $I_{\mathrm{ds}}$ or its square-root for linear or saturation regimes, respectively. 
Capacitance per unit area of the honey/semiconductor interface was extracted from $\mathrm{Au} / \mathrm{honey} / \mathrm{semiconductor} / \mathrm{Au}$ configurations by means of EIS at $0.1 \mathrm{~Hz}$ with a potentiostat (Metrohm Autolab PGstat 302N, Nova 1.8 software) working in a two-electrode configuration. In order to avoid the contribution of Au counter-electrode in the measured complex impedance, its surface area $\left(\sim 7 \mathrm{~cm}^{2}\right)$ was selected to significantly exceed the contact area of the working electrode with semiconductor/Au interface, $\sim 5 \mathrm{~mm}^{2}$. The impedance spectra were recorded in the frequency range from $0.001 \mathrm{~Hz}$ to $100 \mathrm{kHz}$ by applying a continuous bias of $\pm 0.4 \mathrm{~V}$.

\section{Acknowledgements}

M.C. acknowledges partial support from the European Research Council (ERC) under the European Union's Horizon 2020 research and innovation program “ELFO”, Grant Agreement 864299 and under European Union's Horizon 2020 Electronic Smart Systems project “SiMBiT”, Grant Agreement 824946. This work was partially carried out at PoliFab, the micro and nanotechnology center of the Politecnico di Milano. 


\section{References}

[1] M. Irimia-Vladu, Chem. Soc. Rev. 2014, 43, 588.

[2] and S. B. Mihai Irimia-Vladu, Eric D. Glowacki, Niyazi S. Sariciftci, Green Materials for Electronics, Wiley-VCH Verlag GmbH \& Co. KGaA., 2018.

[3] W. Li, Q. Liu, Y. Zhang, C. Li, Z. He, W. C. H. Choy, P. J. Low, P. Sonar, A. K. K. Kyaw, Adv. Mater. 2020, 32, 1.

[4] C. Steiger, A. Abramson, P. Nadeau, A. P. Chandrakasan, R. Langer, G. Traverso, Nat. Rev. Mater. 2019, 4, 83.

[5] A. Abramson, D. Dellal, Y. L. Kong, J. Zhou, Y. Gao, J. Collins, S. Tamang, J. Wainer, R. McManus, A. Hayward, M. R. Frederiksen, J. J. Water, B. Jensen, N. Roxhed, R. Langer, G. Traverso, Sci. Adv. 2020, 6, DOI 10.1126/sciadv.aaz0127.

[6] C. J. Bettinger, Angew. Chemie - Int. Ed. 2018, 57, 16946.

[7] P. R. Chai, R. K. Rosen, E. W. Boyer, Proc. Annu. Hawaii Int. Conf. Syst. Sci. 2016, 2016-March, 3416.

[8] G. P. Flores, T. C. Carnes, S. L. Baumgartner, D. Eric Buffkin, N. R. Euliano, L. N. SMITH, Innov. Clin. Neurosci. 2016, 13, 12.

[9] L. A. Beardslee, G. E. Banis, S. Chu, S. Liu, A. A. Chapin, J. M. Stine, P. J. Pasricha, R. Ghodssi, ACS Sensors 2020, 5, 891.

[10] A. S. Sharova, F. Melloni, G. Lanzani, C. J. Bettinger, M. Caironi, Adv. Mater. Technol. 2020, 6, DOI 10.1002/admt.202000757.

[11] Y. Wu, D. Ye, Y. Shan, S. He, Z. Su, J. Liang, J. Zheng, Z. Yang, H. Yang, W. Xu, H. Jiang, Adv. Mater. Technol. 2020, 5, 1.

[12] M. Irimia-Vladu, P. A. Troshin, M. Reisinger, L. Shmygleva, Y. Kanbur, G. 
Schwabegger, M. Bodea, R. Schwödiauer, A. Mumyatov, J. W. Fergus, V. F.

Razumov, H. Sitter, N. S. Sariciftci, S. Bauer, Adv. Funct. Mater. 2010, 20, 4069.

[13] X. Wang, W. Xu, P. Chatterjee, C. Lv, J. Popovich, Z. Song, L. Dai, M. Y. S. Kalani, S. E. Haydel, H. Jiang, Adv. Mater. Technol. 2016, 1, 1.

[14] W. Xu, H. Yang, W. Zeng, T. Houghton, X. Wang, R. Murthy, H. Kim, Y. Lin, M. Mignolet, H. Duan, H. Yu, M. Slepian, Adv. Mater. Technol. 2017, 2, 1.

[15] I. Jeerapan, B. Ciui, I. Martin, C. Cristea, R. Sandulescu, J. Wang, J. Mater. Chem. B 2018, 6, 3571.

[16] H. Tao, M. A. Brenckle, M. Yang, J. Zhang, M. Liu, S. M. Siebert, R. D. Averitt, M. S. Mannoor, M. C. Mcalpine, J. A. Rogers, D. L. Kaplan, F. G. Omenetto, Adv. Healthc. Mater. 2012, 24, 1067.

[17] M. Irimia-vladu, E. D. Głowacki, P. A. Troshin, G. Schwabegger, L. Leonat, D. K. Susarova, O. Krystal, M. Ullah, Y. Kanbur, M. A. Bodea, V. F. Razumov, H. Sitter, S. Bauer, N. S. Sariciftci, Adv. Mater. 2012, 24, 375.

[18] G. E. Bonacchini, C. Bossio, F. Greco, V. Mattoli, Y. Kim, G. Lanzani, M. Caironi, Adv. Mater. 2018, 30, 1.

[19] J. W. Chang, C. G. Wang, C. Y. Huang, T. D. Tsai, T. F. Guo, T.C. Wen, Adv. Mater. 2011, 23, 4077.

[20] M. Irimia - Vladu, E. D. Glowacki, N. S. Sariciftci, Green Materials for Electronics, Wiley - VCH Verlag GmbH \& Co. KGaA, Weinheim, Germany 2017.

[21] S. H. Kim, K. Hong, W. Xie, K. H. Lee, S. Zhang, T. P. Lodge, C. D. Frisbie, Adv. Mater. 2013, 25, 1822.

[22] D. Wang, V. Noël, B. Piro, Electronics 2016, 5, DOI 10.3390/electronics5010009.

[23] N. Liu, R. Chen, Q. Wan, Sensors (Switzerland) 2019, 19, DOI 10.3390/s19153425.

[24] Y. Sasaki, K. Asano, T. Minamiki, Z. Zhang, S. Takizawa, R. Kubota, T. Minami, 
Chem. - A Eur. J. 2020, 26, 14525.

[25] K. Manoli, M. Magliulo, M. Y. Mulla, M. Singh, L. Sabbatini, G. Palazzo, L. Torsi, Angew. Chemie - Int. Ed. 2015, 54, 12562.

[26] Y. J. Jo, K. Y. Kwon, Z. U. Khan, X. Crispin, T. Il Kim, ACS Appl. Mater. Interfaces 2018, 10, 39083.

[27] L. M. Dumitru, K. Manoli, M. Magliulo, T. Ligonzo, G. Palazzo, L. Torsi, APL Mater. 2015, 3, DOI 10.1063/1.4901124.

[28] S. Mandal, A. Mandal, G. Jana, S. Mallik, A. Ghosh, P. K. Chattaraj, D. K. Goswami, ACS Appl. Mater. Interfaces 2020, 12, 19727-19736.

[29] G. D. Spyropoulos, J. N. Gelinas, D. Khodagholy, Sci. Adv. 2019, 5.

[30] B. Yaman, I. Terkesli, K. M. Turksoy, A. Sanyal, S. Mutlu, Org. Electron. 2014, 15, 646.

[31] R. Furlan, D. Oliveira, L. Merces, T. Parra, Org. Electron. 2016, 31, 217.

[32] L. Kergoat, L. Herlogsson, D. Braga, B. Piro, M. C. Pham, X. Crispin, M. Berggren, G. Horowitz, Adv. Mater. 2010, 22, 2565.

[33] B. G. Sonmez, O. Ertop, S. Mutlu, Sci. Rep. 2017, 7, 27.

[34] F. Scuratti, G. E. Bonacchini, C. Bossio, J. M. Salazar-Rios, W. Talsma, M. A. Loi, M. R. Antognazza, M. Caironi, ACS Appl. Mater. Interfaces 2019, 11, 37966.

[35] D. Blasi, F. Viola, F. Modena, A. Luukkonen, E. MacChia, R. A. Picca, Z. Gounani, A. Tewari, R. Österbacka, M. Caironi, Z. M. Kovacs Vajna, G. Scamarcio, F. Torricelli, L. Torsi, J. Mater. Chem. C 2020, 8, 15312.

[36] E. Macchia, K. Manoli, B. Holzer, C. Di Franco, M. Ghittorelli, F. Torricelli, D. Alberga, G. F. Mangiatordi, G. Palazzo, G. Scamarcio, L. Torsi, Nat. Commun. 2018, 9, DOI 10.1038/s41467-018-05235-z.

[37] P. M. Da Silva, C. Gauche, L. V. Gonzaga, A. C. O. Costa, R. Fett, Food Chem. 2016, 196, 309. 
[38] W. Guo, Yi Liu, X. Zhu, H. Zhuang, Meas. Sci. Technol. 2011, 22, 085706.

[39] N. A. Albaridi, Int. J. Microbiol. 2019, 2019, DOI 10.1155/2019/2464507.

[40] V. C. Nolan, J. Harrison, J. A. G. Cox, Antibiotics 2019, 8, 1.

[41] R. C. Ordonez, C. K. Hayashi, C. M. Torres, J. L. Melcher, G. Severa, D. Garmire, Sci. Rep. 2017, 7, 1.

[42] G. Scarpa, A. L. Idzko, S. Götz, S. Thalhammer, Macromol. Biosci. 2010, 10, 378.

[43] C. Tortiglione, M. R. Antognazza, A. Tino, C. Bossio, V. Marchesano, A. Bauduin, M. Zangoli, S. V. Morata, G. Lanzani, Sci. Adv. 2017, 3.

[44] E. Zucchetti, M. Zangoli, I. Bargigia,C. Bossio, F. Di Maria, G. Barbarella, C.

D’Andrea, G. Lanzani, M. R. Antognazza, J. Mater. Chem. B. 2017, 5, 565.

[45] D. Natali, M. Caironi, Adv. Mater. 2012, 24, 1357.

[46] S. Fabiano, S. Braun, M. Fahlman, X. Crispin, M. Berggren, Adv. Funct. Mater. 2014, 24, 695.

[47] R. A. Picca, K. Manoli, E. Macchia, A. Tricase, C. Di Franco, G. Scamarcio, N. Cioffi, L. Torsi, Front. Chem. 2019, 7, 1.

[48] H. Hintz, H. J. Egelhaaf, L. Lüer, J. Hauch, H. Peisert, T. Chassé, Chem. Mater. 2011, 23, 145.

[49] M. Manceau, A. Rivaton, J. L. Gardette, S. Guillerez, N. Lemaître, Polym. Degrad. Stab. 2009, 94, 898.

[50] Z. Ye, H. Cui, X. Yang, F. Qiu, J. Mater. Chem. C 2015, 3, 1949.

[51] R. Di Pietro, D. Fazzi, T. B. Kehoe, H. Sirringhaus, J. Am. Chem. Soc. 2012, 134, 14877.

[52] H. I. Un, Y. Q. Zheng, K. Shi, J. Y. Wang, J. Pei, Adv. Funct. Mater. 2017, 27, 1.

[53] Q. Bao, X. Liu, S. Braun, J. Yang, Y. Li, J. Tang, C. Duan, M. Fahlman, ACS Appl. Mater. Interfaces 2018, 10, 6491.

[54] J. Chirife and C. F. Fontan, Journal of Food Science 1982, 4, 661. 
[55] S. Yanniotis, S. Skaltsi, S. Karaburnioti, Journal of Food Engineering. 2006, 72, 372.

[56] E. Macchia, R. A. Picca, K. Manoli, C. D. Franco, D. Blasi, L. Sarcina, N. Ditaranto, N. Cioffi, R. Osterbacka, G. Scamarcio, F. Torricelli, L. Torsi, Mater. Horiz., 2020, 7, 999.

[57] X. Li, L. Zhao, J. Yu, X. Liu, X. Zhang, H. Liu, W. Zhou, Nano-Micro Lett. 2020, 12, 1.

[58] R. Porrazzo, A. Luzio, S. Bellani, G. E. Bonacchini, Y. Y. Noh, Y. H. Kim, G. Lanzani, M. R. Antognazza, M. Caironi, ACS Omega 2017, 2, 1.

[59] R. Porrazzo, S. Bellani, A. Luzio, C. Bertarelli, G. Lanzani, M. Caironi, M. R. Antognazza, APL Mater. 2015, 3, DOI 10.1063/1.4900888.

[60] E. C. Martin. Bee World 1958, 39, 165. 


\section{Supporting Information}

\section{Sweet electronics: honey-gated complementary organic transistors and circuits operating in air}

Alina S. Sharova, Mario Caironi*
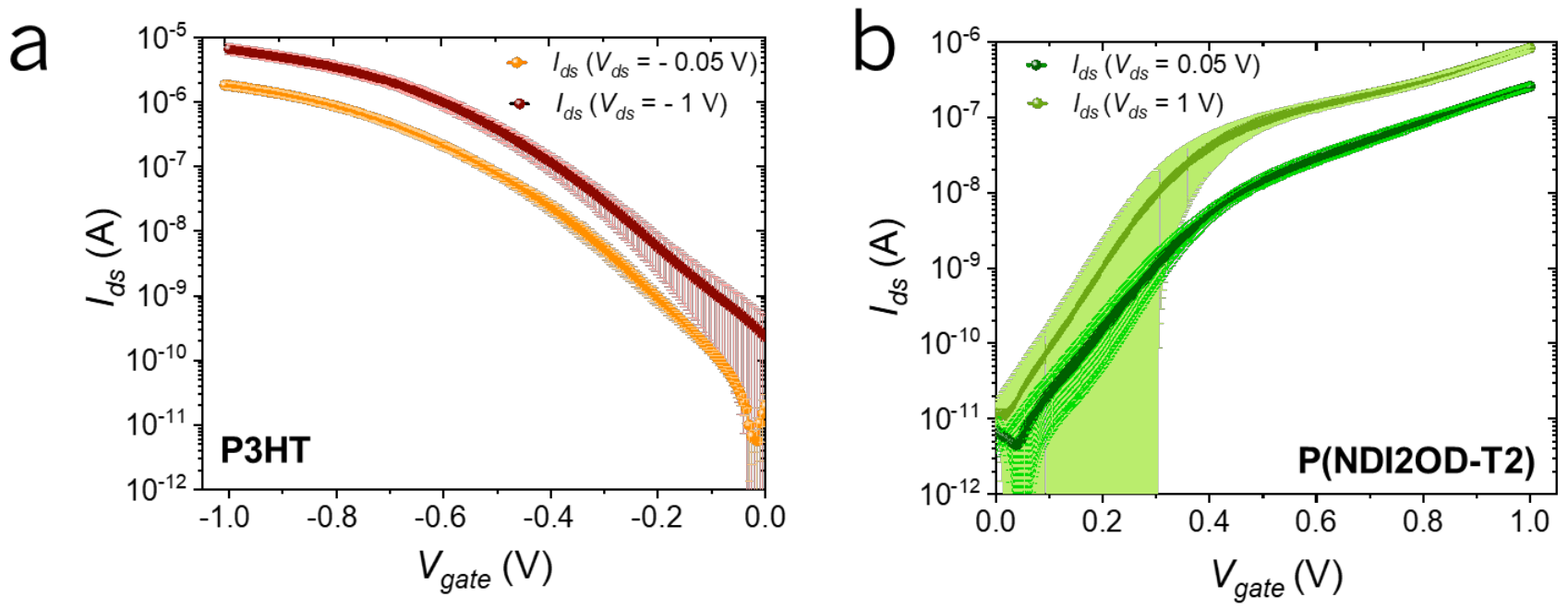

Figure S1. Reproducibility of the HGOFETs. Average transfer characteristic curves among 6 samples for (a) p-type HGOFETs in linear $\left(V_{d s}=-0.05 \mathrm{~V}\right)$ and saturation $\left(V_{d s}=-1 \mathrm{~V}\right)$ regimes and (b) n-type HGOFETs in linear $\left(V_{d s}=0.05 \mathrm{~V}\right)$ and saturation $\left(V_{d s}=1 \mathrm{~V}\right)$ regimes; HGOFETs geometrical parameters: $L=10 \mu \mathrm{m} ; W=20,000 \mu \mathrm{m}$. Shaded area represents standard deviation.

a

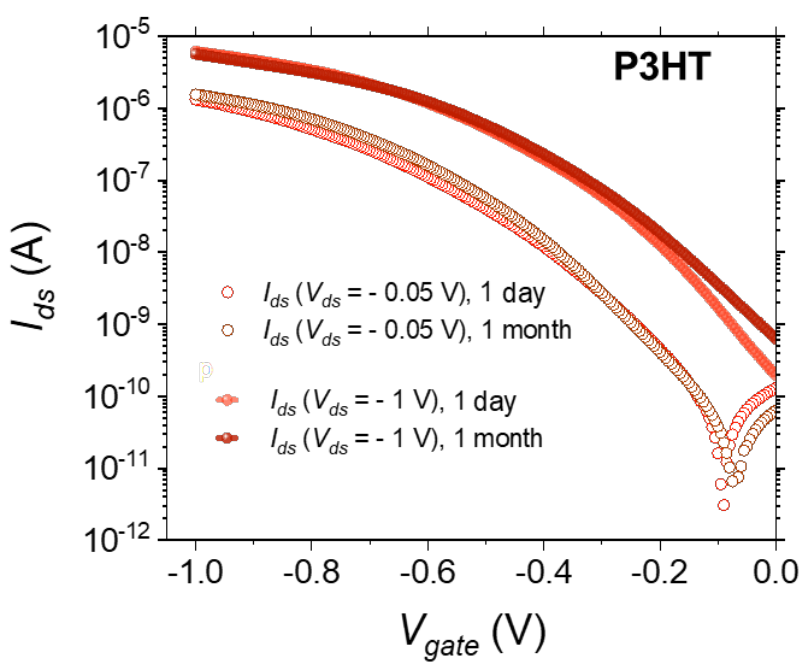

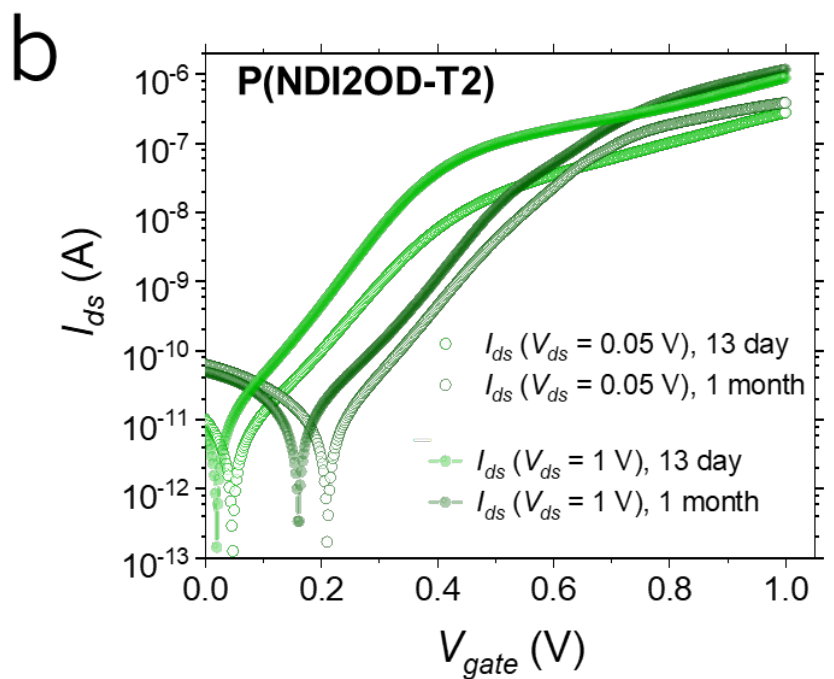

Figure S2. Shelf-life stability of the (a) p-type and (b) n-type HGOFETs. Comparison of electronic performances (transfer characteristics in linear and saturation regimes) after 1-month control period of storing the devices in air. The relative humidity varied from 48.8 to $50.4 \%$, what explains the threshold voltage shift of P(NDI2OD-T2)-based devices to higher values. 

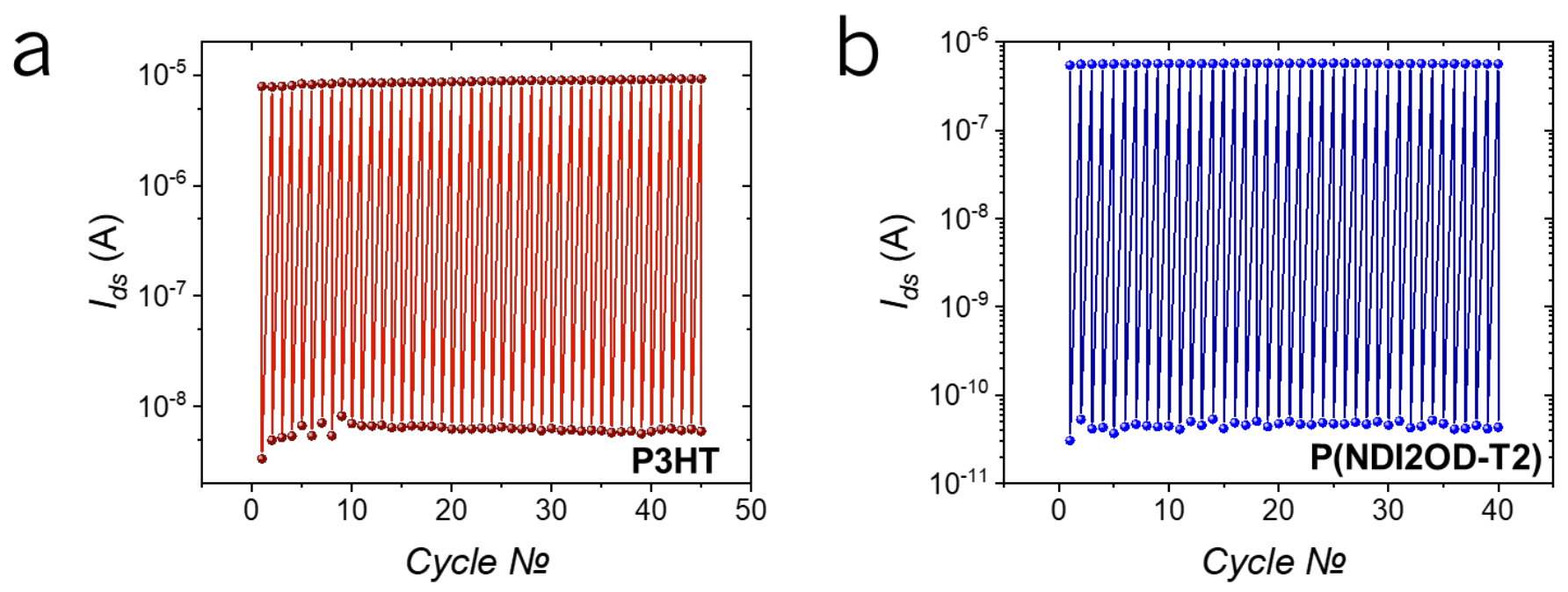

Figure S3. Operational stability of HGOFETs under continuous cycling voltage test in air (cycle duration $40 \mathrm{~s}$, total test duration $30 \mathrm{~min}$ ). The test was carried out by switching (a) the p-type device on $\left(V_{\text {gate }}=-1 \mathrm{~V}, V_{d s}=-0.2 \mathrm{~V}\right.$; ) and off $\left(V_{\text {gate }}=0 \mathrm{~V}, V_{d s}=0.2 \mathrm{~V}\right)$ and (b) n-type HGOFETs on $\left(V_{\text {gate }}=1 \mathrm{~V}, V_{d s}=0.2 \mathrm{~V}\right)$ and off $\left(V_{\text {gate }}=0 \mathrm{~V}, V_{d s}=-0.2 \mathrm{~V}\right)$. No evidence of devices degradation was observed.
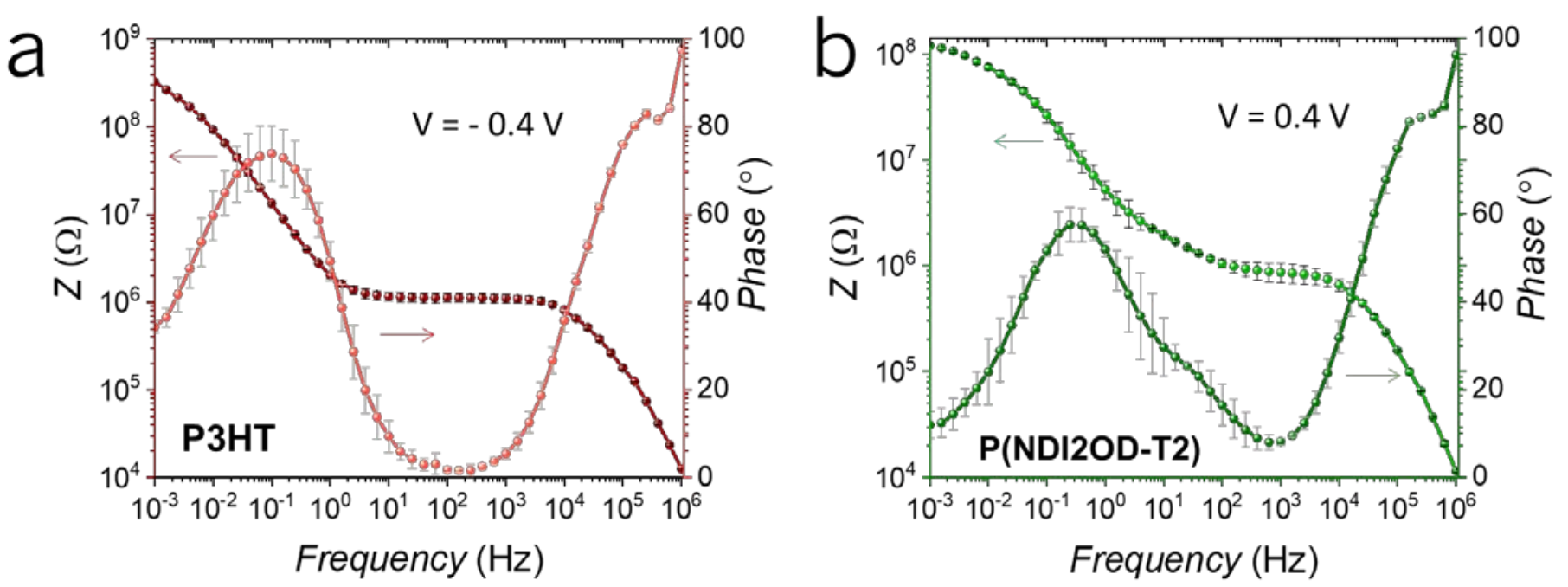

Figure S4. EIS characterization of Au/honey/semiconductor/Au structures based on (a) P3HTand (b) P(NDI2OD-T2) (Au counter-electrode voltage, $\pm 0.4 \mathrm{~V}$, semiconductor/Au interface area $\sim 5 \mathrm{~mm}^{2}$; Au counter-electrode area $\sim 7 \mathrm{~cm}^{2}$ ). Average impedance and phase angle plots among 3 samples. "Hold-time" of $120 \mathrm{~s}$ is set in order to reach a stability. Sampling: 5 points for each decade. 

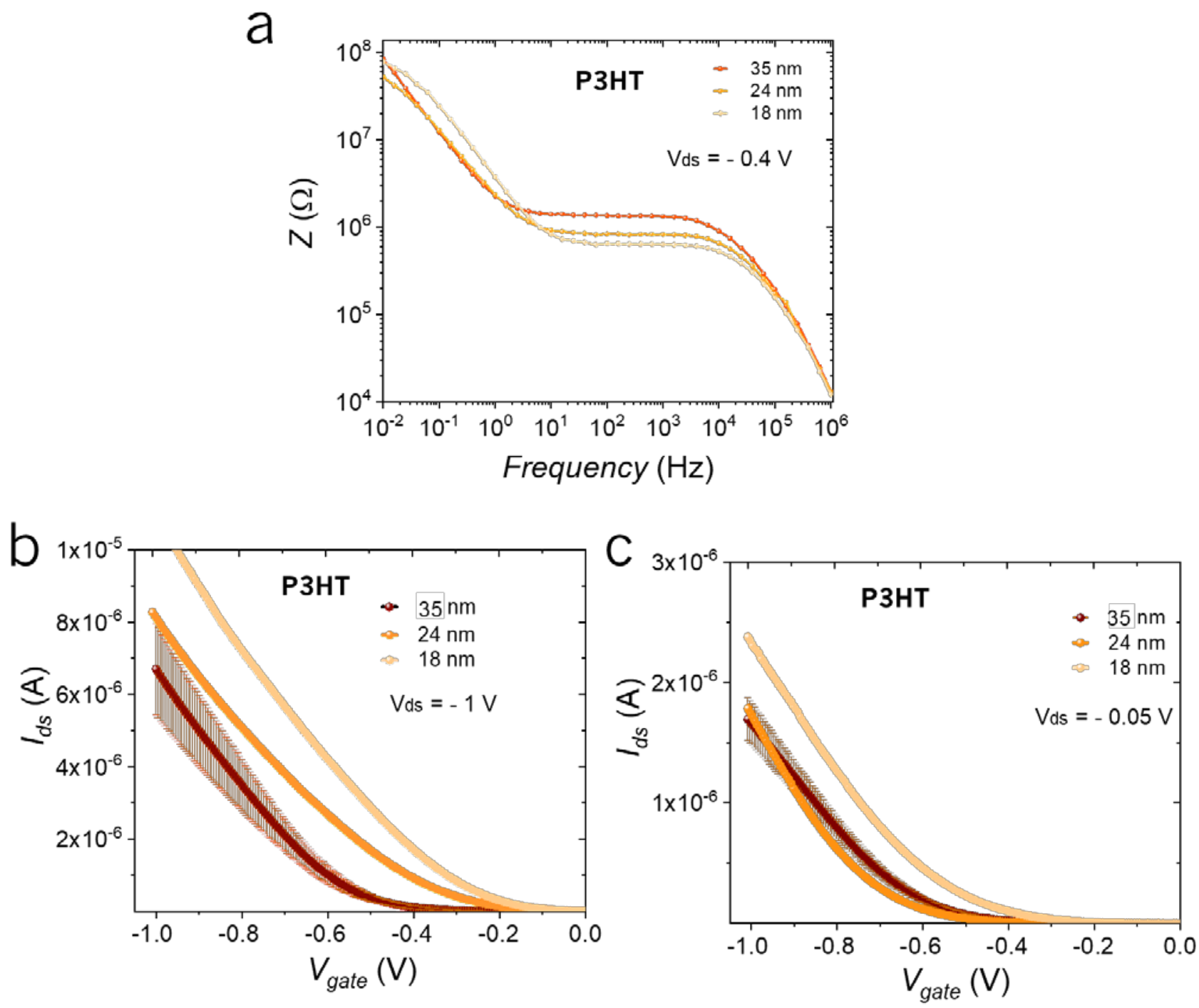

Figure S5. The semiconductor thickness dependence of the electrical performance of p-type devices. (a) EIS characterization of Au/honey/semiconductor/Au structures based on P3HT (Au counter-electrode voltage, $-0.4 \mathrm{~V}$, semiconductor/Au interface area $\sim 5 \mathrm{~mm}^{2}$; Au counterelectrode area $\left.\sim 7 \mathrm{~cm}^{2}\right)$. (b) Transfer characteristic curves in saturation $\left(V_{d s}=-1 \mathrm{~V}\right)$ and (c) linear $\left(V_{d s}=-0.05 \mathrm{~V}\right)$ regimes. 

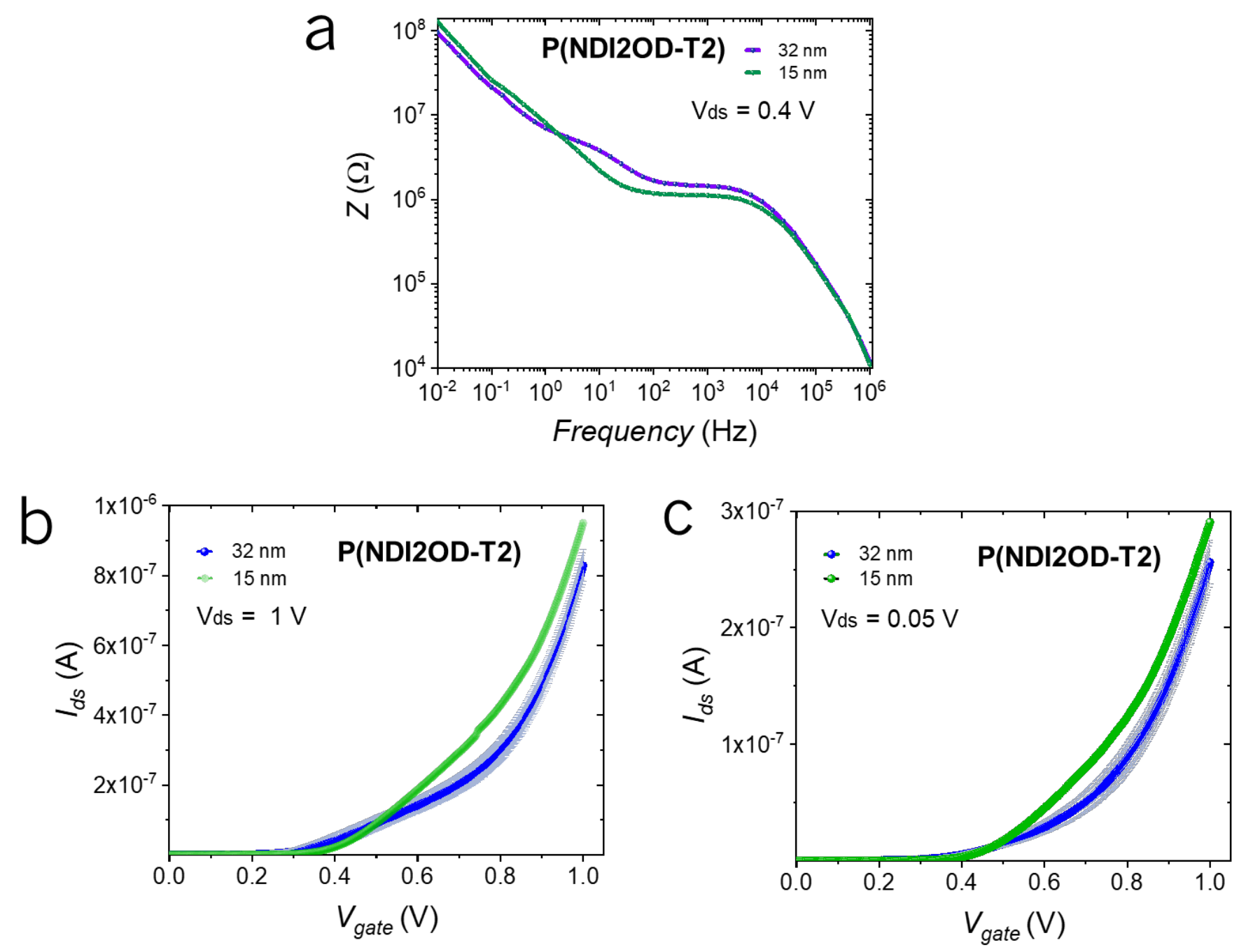

Figure S6. The semiconductor thickness dependence of the electrical performance of n-type devices. (a) EIS characterization of Au/honey/semiconductor/Au structures based on $\mathrm{P}(\mathrm{NDI} 2 \mathrm{OD}-\mathrm{T} 2$ ) (Au counter-electrode voltage, $0.4 \mathrm{~V}$, semiconductor/Au interface area $\sim 5$ $\mathrm{mm}^{2}$; Au counter-electrode area $\left.\sim 7 \mathrm{~cm}^{2}\right)$. (b) Transfer characteristic curves in saturation $\left(V_{d s}=\right.$ $1 \mathrm{~V})$ and $(\mathbf{c})$ linear $\left(V_{d s}=0.05 \mathrm{~V}\right)$ regimes. 

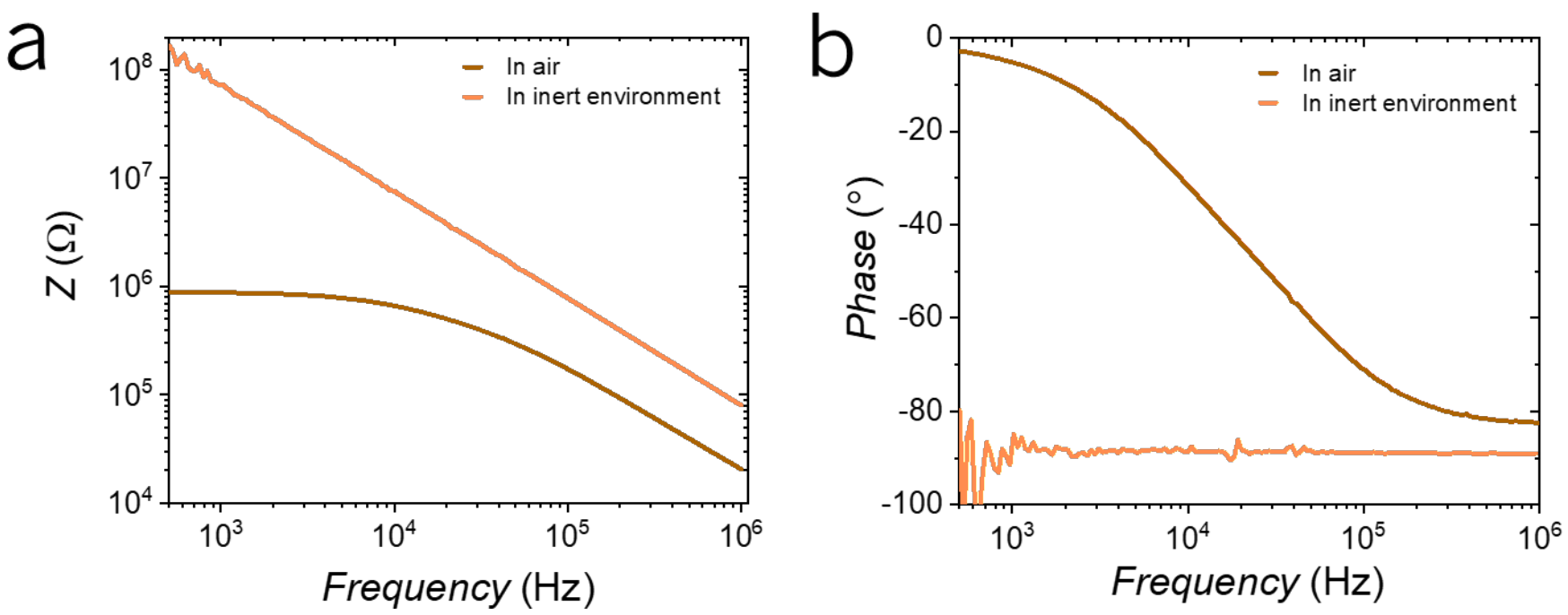

Figure S7. EIS characterization of Au/honey/semiconductor/Au structures based on P3HT in air and in inert environment (Au counter-electrode voltage, $-0.4 \mathrm{~V}$, semiconductor/Au interface area $\sim 5 \mathrm{~mm}^{2}$; Au counter-electrode area $\sim 7 \mathrm{~cm}^{2}$ )
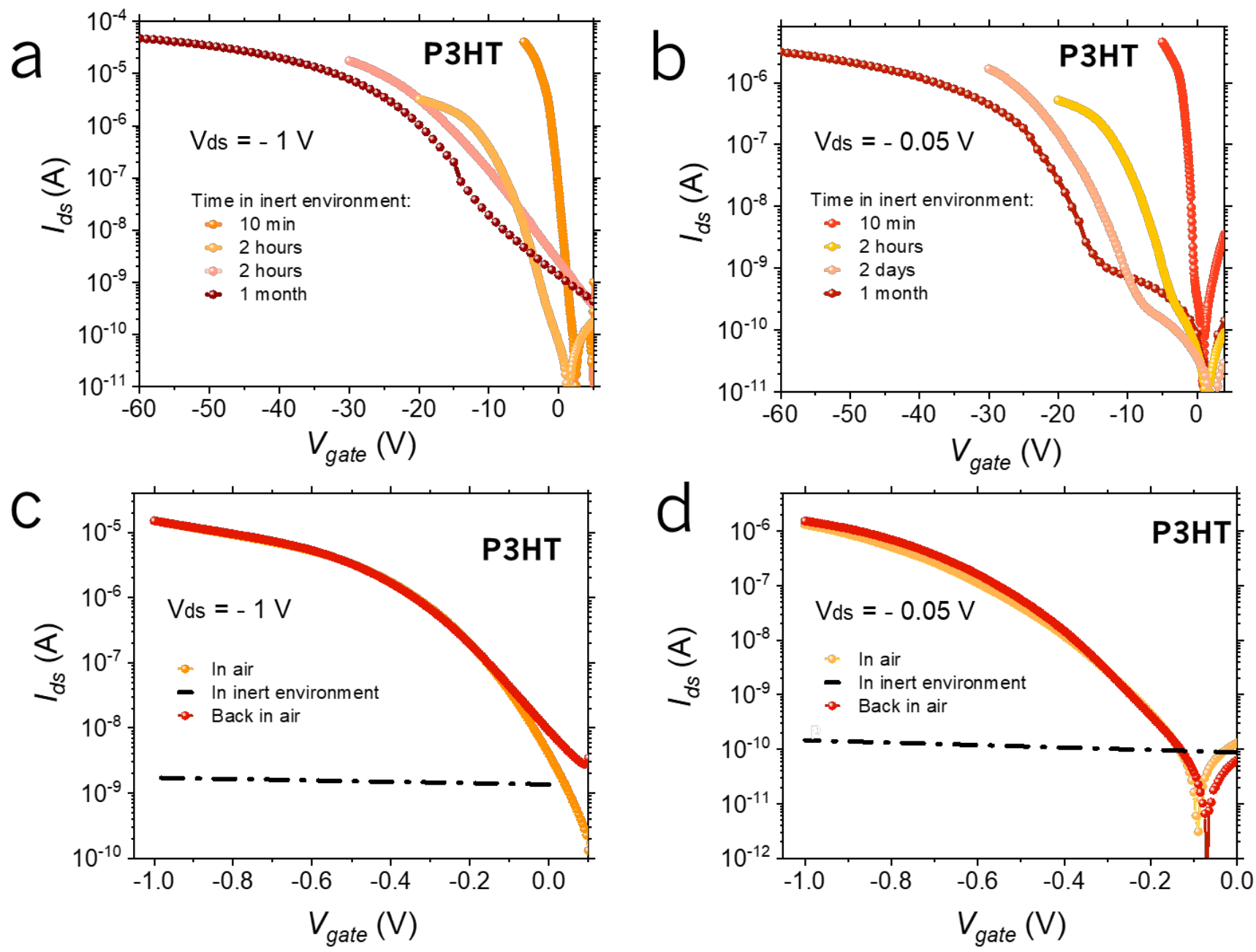
Figure S8. The electrical response of p-type HGOFETs to different humidity conditions (relative humidity in air $\approx 50 \%$; in inert nitrogen environment $\approx 0 \%$ ). The humiditydependent transfer characteristics of p-type HGOFETs operating in both (a, c) saturation $\left(V_{d s}\right.$ $=-1 \mathrm{~V})$ and $(\mathbf{b}, \mathbf{d})$ linear $\left(V_{d s}=-0.05 \mathrm{~V}\right)$ regimes.
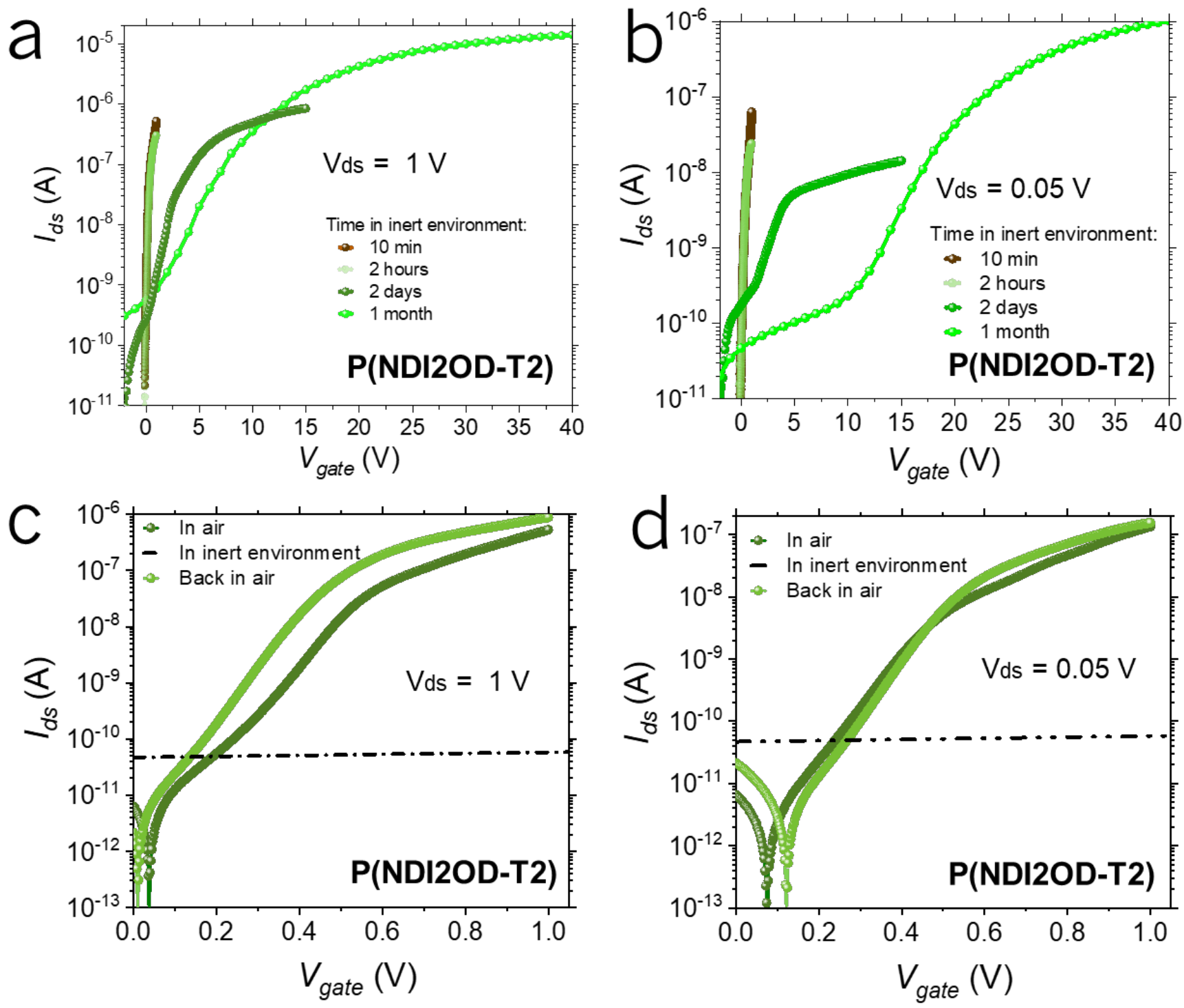

Figure S9. The electrical response of n-type HGOFETs to different humidity conditions (relative humidity in air $\approx 50 \%$; in inert nitrogen environment $\approx 0 \%$ ). The humiditydependent transfer characteristics of n-type HGOFETs operating in both (a, c) saturation $\left(V_{d s}\right.$ $=1 \mathrm{~V})$ and $(\mathbf{b}, \mathbf{d})$ linear $\left(V_{d s}=0.05 \mathrm{~V}\right)$ regimes. 

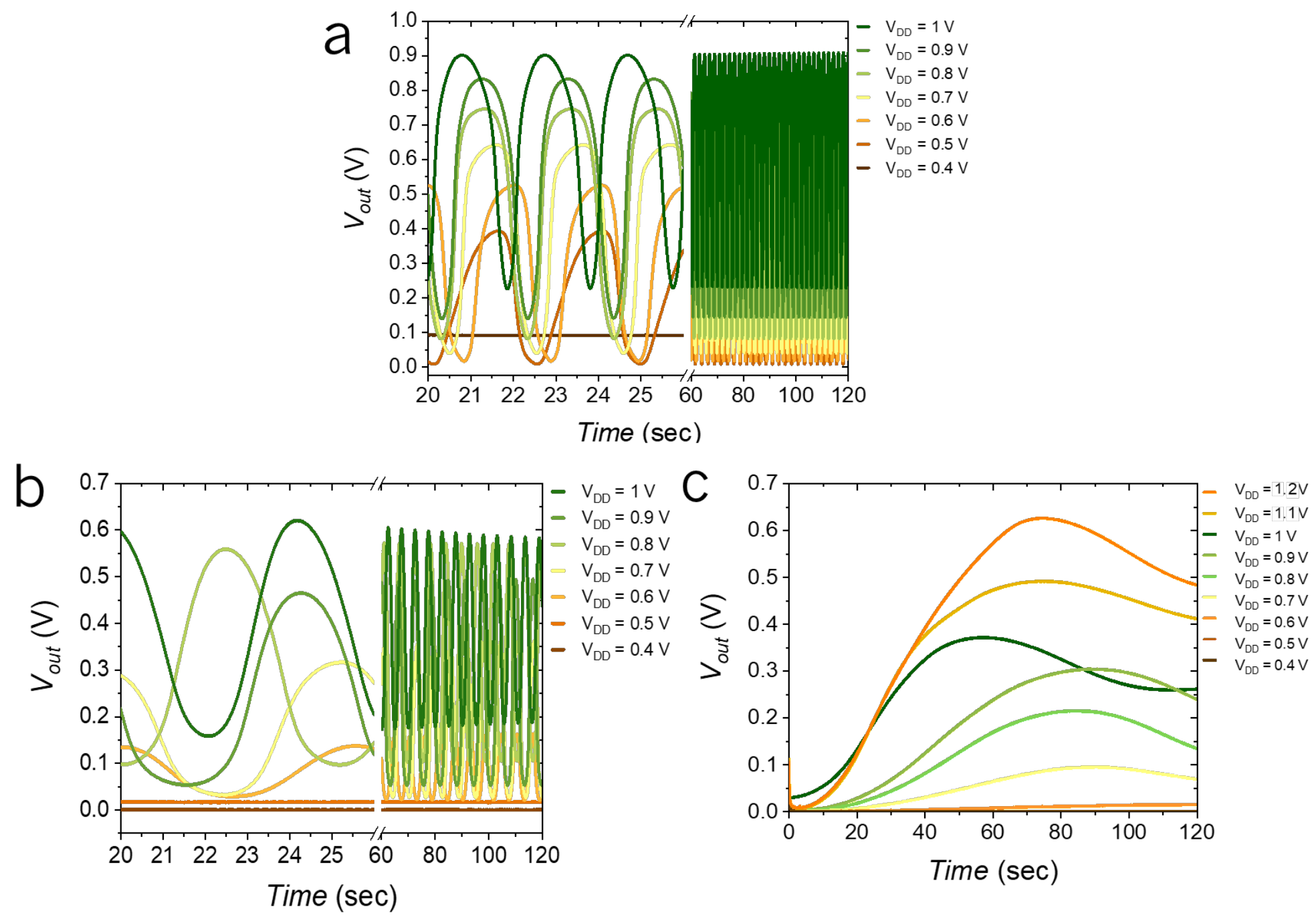

Figure S10. The output waveforms of the HGOFETs-based oscillator at different supply voltages $V_{D D}$ after (a) 10 min; (b) 2 days; (c) 4 days after exposing the device to inert environment. 


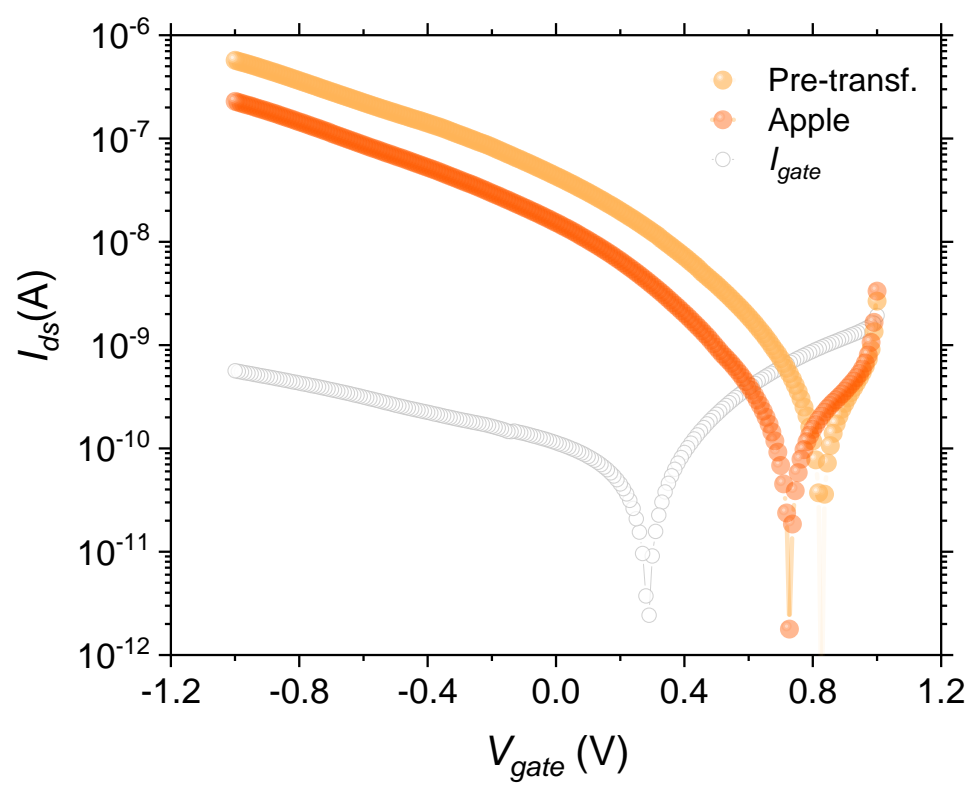

Figure S11. HGOFETs on flexible edible tattoo-paper substrate. Transfer characteristic of p-type HGOFET in saturation $\left(V_{d s}=-0.7 \mathrm{~V}\right)$ regime before and after the transfer onto the apple. (Honey was drop-cast onto the channel area after the transfer procedure) 